\title{
Surgical outcomes after reoperation for recurrent skull base meningiomas
}

\author{
*Stephen T. Magill, MD, PhD, ${ }^{1}$ David S. Lee, BA, ${ }^{1}$ Adam J. Yen, BS, ${ }^{1}$ Calixto-Hope G. Lucas, BS, ${ }^{1}$ \\ David R. Raleigh, MD, PhD, ${ }^{2}$ Manish K. Aghi, MD, PhD, ${ }^{1}$ Philip V. Theodosopoulos, MD, ${ }^{1}$ and \\ Michael W. McDermott, MD ${ }^{1}$
}

Departments of ${ }^{1}$ Neurological Surgery and ${ }^{2}$ Radiation Oncology, University of California, San Francisco, California

OBJECTIVE Skull base meningiomas are surgically challenging tumors due to the intricate skull base anatomy and the proximity of cranial nerves and critical cerebral vasculature. Many studies have reported outcomes after primary resection of skull base meningiomas; however, little is known about outcomes after reoperation for recurrent skull base meningiomas. Since reoperation is one treatment option for patients with recurrent meningioma, the authors sought to define the risk profile for reoperation of skull base meningiomas.

METHODS A retrospective review of 2120 patients who underwent resection of meningiomas between 1985 and 2016 was conducted. Clinical information was extracted from the medical records, radiology data, and pathology data. All records of patients with recurrent skull base meningiomas were reviewed. Demographic data, presenting symptoms, surgical management, outcomes, and complications data were collected. Kaplan-Meier analysis was used to evaluate survival after reoperation. Logistic regression was used to evaluate for risk factors associated with complications.

RESULTS Seventy-eight patients underwent 100 reoperations for recurrent skull base meningiomas. Seventeen patients had 2 reoperations, 3 had 3 reoperations, and 2 had 4 or more reoperations. The median age at diagnosis was 52 years, and $64 \%$ of patients were female. The median follow-up was 8.5 years. Presenting symptoms included cranial neuropathy, headache, seizure, proptosis, and weakness. The median time from initial resection to first reoperation was 4.4 years and 4.1 years from first to second reoperation. Seventy-two percent of tumors were WHO grade I, $22 \%$ were WHO grade II, and $6 \%$ were WHO grade III. The sphenoid wing was the most common location (31\%), followed by cerebellopontine angle (14\%), cavernous sinus (13\%), olfactory groove (12\%), tuberculum sellae $(12 \%)$, and middle fossa floor (5\%). Forty-four (54\%) tumors were $\geq 3 \mathrm{~cm}$ in maximum diameter at the time of the first reoperation. In 100 reoperations, 60 complications occurred in 30 cases. Twenty of the 60 complications required surgical intervention (33\%). Complications included hydrocephalus (12), CSF leak/pseudomeningocele (11), wound infection (9), postoperative hematoma (4), venous infarction (1), and pneumocephalus (1). Postoperative neurological deficits included new or worsened cranial nerve deficits (10) and hemiparesis (3). There were no perioperative deaths in this series. On multivariate analysis, posterior fossa location was significantly associated with complications (OR 3.45, $p=0.0472$ ). The 1-, 2-, 5-, and 10-year overall survival rates according to Kaplan-Meier analysis after the first reoperation were $94 \%, 92 \%, 88 \%$, and $76 \%$, respectively. The median survival after the first reoperation was 17 years.

CONCLUSIONS Recurrent skull base meningiomas are surgically challenging tumors, and reoperation is associated with high morbidity and complication rates. Despite these cautionary data, repeat resection of recurrent skull base meningiomas in appropriately selected patients provides excellent long-term survival.

https://thejns.org/doi/abs/10.3171/2017.11.JNS172278

KEYWORDS meningioma; skull base; reoperation; repeat operation; recurrence; surgery; complications; risk factor

ABBREVIATIONS EBRT = external-beam radiotherapy; EMR = electronic medical record.

SUBMITTED September 15, 2017. ACCEPTED November 14, 2017.

INCLUDE WHEN CITING Published online May 4, 2018; DOI: 10.3171/2017.11.JNS172278.

* S.T.M. and D.S.L contributed equally to this work. 
$\mathrm{M}$ ENINGIOMAS are the most prevalent primary intracranial neoplasm, comprising roughly $30 \%$ of all intracranial tumors. ${ }^{20}$ In the United States, there are more than 170,000 pathologically confirmed cases of meningioma, an underestimation of total meningiomas, considering that only a fraction of these cases are surgically treated..$^{33}$ Roughly one-third of meningiomas arise from the skull base. ${ }^{8}$ Skull base meningiomas are particularly challenging tumors because of their proximity to the cranial nerves, the brainstem, and critical vasculature. .11,17,25,28-30 $^{2}$

Multiple studies have been performed to document the clinical outcomes after primary resection of skull base meningiomas. $3,4,6,7,10,13,16,19,22,24$ However, there is a paucity of published clinical data that addresses the outcomes, risk factors, and overall clinical behavior of recurrent skull base meningiomas after reoperation. Recurrence rates as high as $26 \%-29 \%$ for skull base meningiomas have been reported, yet there are few data to inform patients and surgeons regarding the management of these tumors. ${ }^{6,18}$

The objective in this study was to evaluate and report surgical outcomes for patients who underwent reoperations for skull base meningiomas, including survival and complication rates, and to identify risk factors for complications after reoperation. To our knowledge, this is the largest surgical series of reoperations for recurrent skull base meningiomas published in the literature to date.

\section{Methods}

\section{Study Design, Setting, Participants, and Inclusion Criteria}

A retrospective cohort study was conducted to identify patients who underwent meningioma resection between 1985 and 2016 at our institution. Clinical information on 2120 patients who underwent meningioma resection was screened to identify patients who had undergone reoperation for recurrent skull base meningiomas. Of the 2120 meningiomas, 928 were in a skull base location. The study setting was a large academic medical center with a broad referral base and busy neurosurgical service. The number of treated patients who met the inclusion criteria determined the study size. Inclusion criteria for this study were patients who 1) were older than 18 years; 2) had confirmed recurrent skull base meningiomas; 3 ) underwent repeat resection after recurrence; and 4) had an electronic medical record (EMR) that contained at least a pathology report, an operative report, and admission/discharge information. Tumors were classified as follows. Anterior fossa tumors included olfactory groove, planum sphenoidale, tuberculum sellae, and parasellar tumors. Middle fossa tumors included cavernous sinus, clinoidal, and sphenoid wing tumors. Posterior fossa tumors included petroclival, cerebellopontine angle/petrous face, jugular foramen, and foramen magnum tumors. The committee on human research/ institutional review board approved the study. The manuscript was prepared according to the STROBE criteria. ${ }^{31}$

\section{Data Sources, Variables, and Bias}

Data were collected from the EMRs, radiological archives, and pathology reports. Recorded clinical variables included age, sex, presenting symptoms, tumor location, tumor size, pathology, radiation treatment, time between diagnosis and first reoperation, complications, and mortality. Tumor location along the skull base and preoperative tumor size were evaluated using preoperative postcontrast T1-weighted MRI and based on the largest diameter recorded in the radiology report. The locations of multifocal tumors were assigned to the location with the largest tumor. The location was based on the primary dural attachment. Tumor grade was taken from the surgical pathology report and was based on the contemporary WHO grade at the time of treatment. Mortality data were obtained from the Social Security Death Index and the EMR. Demographic information, presenting symptoms, and medical and surgical complications were gathered from the EMR and were based on the surgical team's assessments in the operative notes, admission/discharge summaries, and progress notes. Thus, the results of this retrospective study are subject to selection bias and observer bias. No patients who had information regarding the variables of interest in the chart were excluded, thus limiting selection bias. This study is limited by observer bias in that only information that was recorded in the chart could be used. Any complications or clinical variables that were not recorded, but did occur, could impact the results.

\section{Statistical Analysis}

All descriptive and statistical analyses were performed using JMP (version 13.0, SAS Institute Inc.). Univariate Pearson chi-square tests were performed to establish associations between surgical outcomes and clinical variables. All clinical variables with $\mathrm{p} \leq 0.2$ were included in subsequent multivariate logistic regressions for multivariate analysis of risk factors associated with complications. Significance was defined at $\mathrm{p}<0.05$. The Kaplan-Meier method was used to calculate progression-free and overall survival. Patients were censored based on the last recorded follow-up or death confirmed by the Social Security Death Index or EMR.

\section{Results}

\section{Participant Demographics}

In the 2120 patients who underwent resection of meningiomas at our institution, 928 (44\%) tumors were located on the skull base. Among these patients, 78 (3.7\%) were identified as having undergone at least one reoperation for a recurrent skull base meningioma after the primary resection. Initial presenting symptoms at the primary surgery are presented in Table 1. Information on presenting symptoms was unavailable due to a lack of preoperative EMRs for 4 patients $(5.1 \%)$ who underwent primary resection at outside facilities. All patients who presented for reoperation had tumor growth on serial postoperative imaging. The median follow-up was 8.5 years.

Of the 78 patients with recurrence, $72 \%$ had WHO grade I meningiomas, $22 \%$ had WHO grade II meningiomas, and $6.4 \%$ had WHO grade III meningiomas (Table 2). WHO grade was based on the WHO grading criteria at the time of pathological diagnosis. Tumor locations are presented in Table 2; the majority of tumors were in the middle fossa. The sphenoid wing was the most common 
TABLE 1. Patient characteristics

\begin{tabular}{lc}
\hline \multicolumn{1}{c}{ Variable } & Value \\
\hline No. of patients & 78 \\
\hline Median age at 1st reop in yrs (range) & $52(20-88)$ \\
\hline Median follow-up after Dx in yrs (range) & $8.5(1-33)$ \\
\hline \% female sex & 64 \\
\hline Initial presenting symptoms, n (\%) & $23(30)$ \\
\hline Headache & $10(13)$ \\
\hline Seizure & $10(13)$ \\
\hline Proptosis & $3(3.8)$ \\
\hline Weakness & $20(26)$ \\
\hline Cranial neuropathy & $5(6.4)$ \\
\hline CN II & $1(1.3)$ \\
\hline CNs III, IV, \& VI & $12(15)$ \\
\hline CN V & $2(2.6)$ \\
\hline CN VII & $3(3.9)$ \\
\hline CN VIII & $2(2.6)$ \\
\hline CNs IX, X, \& XII & $4(5.1)$ \\
\hline Incidental &
\end{tabular}

$\mathrm{CN}=$ cranial nerve; $\mathrm{Dx}=$ diagnosis.

location (31\%). The largest tumor diameter in any plane was used as a proxy for tumor size. The majority of tumors were $\geq 3 \mathrm{~cm}$ in at least one diameter at recurrence, and thus were not amenable to radiation therapy or had grown despite radiation therapy. Information on tumor size was unavailable due to a lack of EMRs and/or inaccessible studies in the picture archiving and communication system for 8 reoperations (8.0\%). Seventy-eight patients underwent a total of 100 reoperations for recurrent skull base meningioma. Of the 78 patients who had at least 1 reoperation, 17 patients went on to have a second reoperation, 3 patients went on to have a third reoperation, and 2 patients went on to have 4 or more reoperations. Many patients also underwent radiation therapy or stereotactic radiosurgery in the intervals between each operation. These data are presented in Table 3 (see Table 5 for further details on radiation therapy).

\section{Survival Outcomes After Surgery for Skull Base Meningiomas}

Kaplan-Meier survival analysis was performed (Fig. 1). A total of 12 patients died during the follow-up period. The median survival after initial diagnosis was 26.6 years (Fig. 1A). Survival rates at 5, 10, and 20 years after initial diagnosis were $95 \%, 88 \%$, and $69 \%$, respectively. Median survival after the first reoperation was 17.1 years, with 2-, $5-, 10-$, and 20 -year survival rates of $92 \%, 88 \%, 76 \%$, and $40 \%$, respectively (Fig. 1B). Median survival after the second reoperation was 12.2 years, with 2-, 5-, and 10-year survival rates of $92 \%, 77 \%$, and $29 \%$, respectively (Fig. 1C).

\section{Complications After Reoperation for Recurrent Skull Base Meningiomas}

There were 60 complications that occurred after 30 of
TABLE 2. Tumor characteristics

\begin{tabular}{|c|c|}
\hline Variable & Value* \\
\hline \multicolumn{2}{|l|}{ WHO grade } \\
\hline I & $56(72)$ \\
\hline II & $17(22)$ \\
\hline III & $5(6)$ \\
\hline \multicolumn{2}{|l|}{ Location } \\
\hline Anterior fossa & $21(27)$ \\
\hline Olfactory groove & $9(12)$ \\
\hline Tuberculum sellae & $9(12)$ \\
\hline Planum sphenoidale & $2(3)$ \\
\hline Dorsum sellae & $1(1)$ \\
\hline Middle fossa & $39(50)$ \\
\hline Sphenoid wing & $24(31)$ \\
\hline Cavernous sinus & $10(13)$ \\
\hline Middle fossa floor & $4(5)$ \\
\hline Clinoid & $1(1)$ \\
\hline Posterior fossa & $18(23)$ \\
\hline Cerebellopontine angle & $11(14)$ \\
\hline Petroclival & $3(4)$ \\
\hline Cerebellar convexity & $2(3)$ \\
\hline Foramen magnum & $1(1)$ \\
\hline Jugular foramen & $1(1)$ \\
\hline \multicolumn{2}{|l|}{ Largest tumor diameter in $\mathrm{cm}$} \\
\hline \multicolumn{2}{|l|}{ 1st reop $(n=78)$} \\
\hline Median (range) & $3.2(1.4-8.0)$ \\
\hline$<3$ & $27(35)$ \\
\hline$\geq 3$ & $44(56)$ \\
\hline Unknown & $7(9.0)$ \\
\hline \multicolumn{2}{|l|}{ 2nd reop $(n=17)$} \\
\hline Median (range) & $4.0(2.0-9.4)$ \\
\hline$<3$ & $6(35)$ \\
\hline$\geq 3$ & $10(59)$ \\
\hline Unknown & $1(5.9)$ \\
\hline \multicolumn{2}{|l|}{3 rd reop $(n=3)$} \\
\hline Median (range) & $6.0(2-7.1)$ \\
\hline$<3$ & $1(33)$ \\
\hline$\geq 3$ & $2(67)$ \\
\hline \multicolumn{2}{|l|}{ 4th reop $(n=2)$} \\
\hline Median (range) & $5.1(3.6-6.5)$ \\
\hline$<3$ & 0 \\
\hline$\geq 3$ & $2(100)$ \\
\hline
\end{tabular}

Values are presented as the number of tumors (\%) unless stated otherwise.

the 100 reoperations (Table 4). Multiple complications occurred in 11 patients. Of the 60 complications, 20 (33\%) required additional surgical intervention. Complications included hydrocephalus (12), CSF leak/pseudomeningocele (11), wound infection (9), postoperative hematoma (4), venous infarct (1), and pneumocephalus (1). Postoperative new or worsened cranial nerve deficits occurred after 13 operations (13\%): 10 cases of cranial nerve deficits and 3 
TABLE 3. Reoperation and interval treatment data

\begin{tabular}{lrrrr}
\hline \multicolumn{1}{c}{ Variable } & 1st Reop & 2nd Reop & 3rd Reop & 4th Reop \\
\hline No. of patients & 78 & 17 & 3 & 2 \\
\hline Median age at surgery in yrs (range) & $52(20-88)$ & $53(31-79)$ & $43(31-44)$ & $45(34-56)$ \\
\hline Median time since prior surgery in yrs (range) & $4.4(1-24)$ & $4.1(1-28)$ & $2.6(1-12)$ & $6.9(2-12)$ \\
\hline Median postop follow-up in yrs (range) & $3.1(1-28)$ & $1.9(1-24)$ & $12(5-12)$ & $1.5(1-2)$ \\
\hline Interval treatment since prior surgery, $\mathrm{n}(\%)$ & & & & \\
\hline EBRT & $8(10)$ & $2(12)$ & 0 & 0 \\
\hline Gamma Knife radiosurgery & $11(14)$ & $3(18)$ & 0 & $1(50)$ \\
\hline
\end{tabular}

of hemiparesis. We did not consider transient deficits that fully recovered by the first postoperative visit as a complication. There were 9 medical complications (Table 4). There were no perioperative deaths. Complications requiring additional operations included hydrocephalus (12 required ventriculoperitoneal shunts), CSF leak/pseudomeningocele (2 required ventriculoperitoneal shunts), and wound infections (6 required wound washouts).

For the 17 patients who underwent at least 2 reoperations, 7 (41\%) had complications (Table 4). There were 14 total complications, of which 2 were medical and 12 surgical. Five of the surgical complications required additional surgery. Of the 3 patients who underwent a third reoperation, there were a total of 4 complications. Of the 2 patients who underwent a fourth reoperation, there was 1 complication. This patient developed hydrocephalus and required a ventriculoperitoneal shunt.

To determine what risk factors were associated with an increased risk of complications, we performed univariate analysis with Pearson chi-square tests for the following

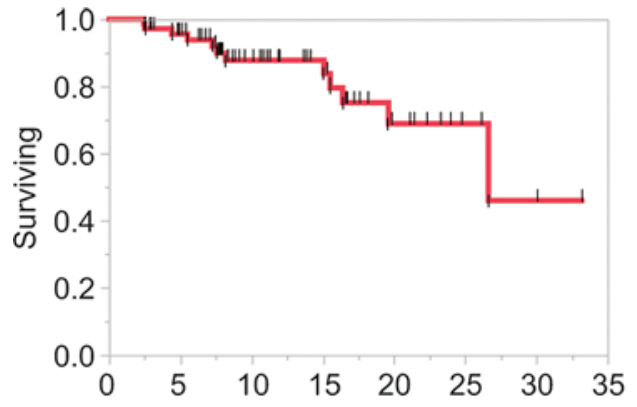

A Survival after initial diagnosis (yrs)

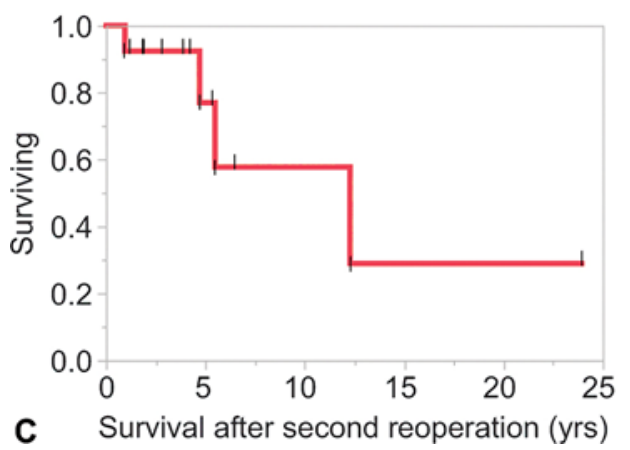

variables: sex, age, tumor grade, location, size, interval radiotherapy, number of reoperations, presenting symptoms, and time from diagnosis to first reoperation (Table 5). The primary outcome was any complication after the first reoperation. We did not analyze risk factors for complications after second, third, or fourth reoperations because the small number of complications was inadequate to perform meaningful statistical analysis. We did evaluate the wound infection/breakdown/CSF leak outcome separately and found no increased rate of wound healing problems with prior interval radiation therapy $(\mathrm{p}=0.9657)$. Only posterior fossa location was significantly associated with an increased risk of any complication $(p=0.0148)$. We also performed univariate logistic regression to determine if the modality of radiation therapy (fractionated externalbeam radiation therapy [EBRT], stereotactic radiosurgery, or both) had an impact on complications (Table 5). There was no significant association between an individual modality of radiation therapy and occurrence of any complication $(p=0.3867)$. Multivariate logistic regression was

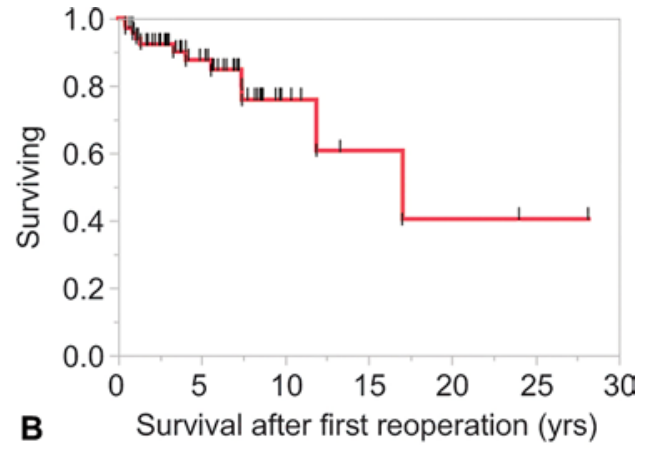

FIG. 1. Kaplan-Meier survival curves. A: Survival after initial diagnosis. B: Survival after first reoperation. C: Survival after second reoperation. Figure is available in color online only. 
TABLE 4. Complications

\begin{tabular}{|c|c|c|c|c|c|}
\hline Variable & 1st Reop & 2nd Reop & 3rd Reop & 4th Reop & Total \\
\hline No. of patients at each reop & 78 & 17 & 3 & 2 & 100 \\
\hline No. of patients w/ complication (\%) ${ }^{*}$ & $25(32)$ & $7(41)$ & $2(67)$ & $1(50)$ & $30(30)$ \\
\hline Total no. of complications & 41 & 14 & 4 & 1 & 60 \\
\hline Complications requiring surgery & 13 & 5 & 1 & 1 & 20 \\
\hline \multicolumn{6}{|l|}{ Surgical } \\
\hline Hydrocephalus & 8 & 2 & 1 & 1 & 12 \\
\hline Required shunt & 8 & 2 & 1 & 1 & 12 \\
\hline CSF leak/pseudomeningocele & 8 & 3 & & & 11 \\
\hline Required lumbar drain & 2 & & & & 2 \\
\hline Required shunt & 1 & 1 & & & 2 \\
\hline Wound infection & 6 & 3 & & & 9 \\
\hline Required surgery & 4 & 2 & & & 6 \\
\hline Postop hematoma & 3 & 1 & & & 4 \\
\hline Hemiparesis & 2 & 1 & & & 3 \\
\hline \multicolumn{6}{|l|}{ Cranial neuropathies } \\
\hline Transient vision decline & 1 & & & & 1 \\
\hline Diplopia & 1 & 1 & & & 2 \\
\hline Loss of lateral gaze & 2 & & 1 & & 3 \\
\hline Decreased facial sensation & 1 & & & & 1 \\
\hline Facial weakness & 1 & & & & 1 \\
\hline Vertigo & 1 & & & & 1 \\
\hline Vocal cord paralysis & 1 & & & & 1 \\
\hline Venous infarct & 1 & & & & 1 \\
\hline Pneumocephalus & & 1 & & & 1 \\
\hline \multicolumn{6}{|l|}{ Medical } \\
\hline Deep venous thrombosis & 2 & & & & 2 \\
\hline Pneumonia & & 1 & 1 & & 2 \\
\hline Hyponatremia & 1 & 1 & & & 2 \\
\hline Adult respiratory distress syndrome & & & 1 & & 1 \\
\hline Atrial fibrillation & 1 & & & & 1 \\
\hline Urinary tract infection & 1 & & & & 1 \\
\hline
\end{tabular}

* Total is all individual patients who had a complication (some had complications after multiple operations).

performed on variables that had a significance of $\mathrm{p} \leq 0.2$, including tumor location, maximal tumor diameter $\geq 3$ $\mathrm{cm}$, radiotherapy prior to reoperation, and seizure at initial presentation. Only posterior fossa location was significantly associated with complication after first reoperation (OR 3.45, p = 0.0472) on multivariate analysis (Table 6).

\section{Discussion \\ Key Results}

The objective of this study was to report surgical outcomes after reoperation for skull base meningiomas and identify risk factors for complications in the largest series to date. Here, we presented data showing that despite a high complication rate, reoperation for recurrent meningiomas leads to excellent long-term survival without mortality. Furthermore, we showed that reoperation for posterior fossa meningiomas is associated with an increased risk of postoperative complications.

\section{Interpretation}

The principal finding of our report is the high complication rate after repeat surgery for recurrent skull base meningiomas. This finding is not to be taken lightly-in 78 patients undergoing 100 reoperations, 30 patients had a total of 60 complications, of which 20 required surgical intervention. When compared with complication rates reported for initial resection of symptomatic meningiomas $\left(21.7 \%\right.$; 87 complications/401 surgeries), ${ }^{34}$ atypical meningiomas (12.9\%; 8 complications/62 surgeries), ${ }^{14}$ and WHO grade III meningiomas (19\%; 12 complications/63 patients) ${ }^{26}$ complication rates for reoperation of skull base meningiomas are still considerably higher.

Despite the high complication rate, there was no perioperative mortality in this large series. Furthermore, survival rates were very good, with 5- and 10-year rates after the first reoperation reaching $88 \%$ and $76 \%$, respectively, based on Kaplan-Meier analysis. In our series, the 
TABLE 5. Univariate analysis of risk factors for any complication after the first reoperation

\begin{tabular}{|c|c|c|c|}
\hline \multirow[b]{2}{*}{ Variable } & \multicolumn{2}{|c|}{ No. of Patients (\%) } & \multirow[b]{2}{*}{$\begin{array}{c}\mathrm{p} \\
\text { Value* }\end{array}$} \\
\hline & $\begin{array}{c}\text { No } \\
\text { Complication }\end{array}$ & $\begin{array}{c}\text { Any } \\
\text { Complication }\end{array}$ & \\
\hline \multicolumn{4}{|l|}{ Sex } \\
\hline Male & $17(21)$ & $11(14)$ & \multirow{2}{*}{0.3056} \\
\hline Female & $36(46)$ & $14(18)$ & \\
\hline \multicolumn{4}{|l|}{ Age $(x)$ at 1 st reop in yrs } \\
\hline$x<40$ & $14(18)$ & $3(3.8)$ & \multirow{5}{*}{0.4780} \\
\hline $40 \leq x<50$ & $15(19)$ & $7(9.0)$ & \\
\hline $50 \leq x<60$ & $12(15)$ & $8(10)$ & \\
\hline $60 \leq x<70$ & $8(10)$ & $3(3.8)$ & \\
\hline $70 \leq x$ & $4(5.1)$ & $4(5.1)$ & \\
\hline \multicolumn{4}{|l|}{ WHO Grade } \\
\hline I & $38(49)$ & $18(23)$ & \multirow{3}{*}{0.8123} \\
\hline II & $11(14)$ & $6(7.6)$ & \\
\hline III & $4(5.1)$ & $1(1.3)$ & \\
\hline \multicolumn{4}{|l|}{ Tumor location } \\
\hline Non-posterior fossa & $45(58)$ & $15(19)$ & \multirow{2}{*}{0.0148} \\
\hline Posterior fossa & $8(10)$ & $10(13)$ & \\
\hline \multicolumn{4}{|l|}{$\begin{array}{l}\text { Max tumor diameter at } 1 \mathrm{st} \\
\text { reop in } \mathrm{cm}\end{array}$} \\
\hline$\geq 3$ & $27(38)$ & $17(24)$ & \multirow{2}{*}{0.1514} \\
\hline$<3$ & $21(30)$ & $6(8.5)$ & \\
\hline \multicolumn{4}{|l|}{ RT before 1st reop } \\
\hline No radiotherapy & $40(51)$ & $22(28)$ & \multirow{2}{*}{0.2010} \\
\hline Any RT (EBRT, SRS) & $13(17)$ & $3(3.9)$ & \\
\hline \multicolumn{4}{|l|}{$\mathrm{RT}$ before 1st reop } \\
\hline No RT & $40(51)$ & $22(28)$ & \multirow{4}{*}{0.3867} \\
\hline Fractionated RT (EBRT) & $5(6)$ & $0(0)$ & \\
\hline SRS & $4(5)$ & $1(1)$ & \\
\hline Both (EBRT + SRS) & $4(5)$ & $2(3)$ & \\
\hline \multicolumn{4}{|l|}{ Seizure at presentation } \\
\hline No & $40(54)$ & $22(30)$ & \multirow{2}{*}{0.2025} \\
\hline Yes & $10(14)$ & $2(2.7)$ & \\
\hline \multicolumn{4}{|l|}{ Weakness at presentation } \\
\hline No & $48(65)$ & $23(31)$ & \multirow{2}{*}{0.9729} \\
\hline Yes & $2(2.7)$ & $1(1.4)$ & \\
\hline \multicolumn{4}{|c|}{$\begin{array}{l}\text { Cranial neuropathy at presen- } \\
\text { tation }\end{array}$} \\
\hline No & $31(42)$ & $12(16)$ & \multirow{2}{*}{0.3274} \\
\hline Yes & $19(26)$ & $12(16)$ & \\
\hline \multicolumn{4}{|l|}{ Headache at presentation } \\
\hline No & $34(46)$ & $17(23)$ & \multirow{2}{*}{0.8053} \\
\hline Yes & $16(22)$ & $7(9.5)$ & \\
\hline Time from Dx to 1st reop in & & & \\
\hline$<5$ & $31(40)$ & $13(17)$ & \\
\hline $5-10$ & $16(21)$ & $6(7.7)$ & 0.2360 \\
\hline$>10$ & $5(6.5)$ & $6(7.8)$ & \\
\hline
\end{tabular}

$\mathrm{RT}$ = radiation therapy; SRS = stereotactic radiosurgery.

Boldface type indicates statistical significance.

* Pearson's chi-square test.
TABLE 6. Multivariate analysis of risk factors for any complication after the first reoperation

\begin{tabular}{lccc}
\hline \multicolumn{1}{c}{ Variable } & $\begin{array}{c}\text { Any Complication } \\
\text { OR }\end{array}$ & $95 \% \mathrm{Cl}$ & $\begin{array}{c}\mathrm{p} \\
\text { Value }\end{array}$ \\
\hline Posterior fossa location & 3.45 & $1.01-11.74$ & $\mathbf{0 . 0 4 7 2}$ \\
\hline Max tumor diameter $\geq 3 \mathrm{~cm}$ & 2.46 & $0.75-8.08$ & 0.1360 \\
\hline RT prior to 1st reop & 0.49 & $0.11-2.15$ & 0.3408 \\
\hline Seizure at presentation & 0.45 & $0.08-2.47$ & 0.3596 \\
\hline
\end{tabular}

Boldface type indicates statistical significance.

strongest predictor of complication was posterior fossa tumor location. This is perhaps unsurprising, as meningiomas within the posterior fossa are frequently adherent to critical structures, and Simpson grade I resection is often not possible, even in the most capable hands. Thus, the complication rates reported here may inform surgeons as they discuss treatment options with patients who experience recurrent meningiomas, especially when the tumor is small or spread out along the dura "en plaque," like a carpet.

Tumor size is also an important consideration when determining surgical management strategies for recurrent meningioma. Larger tumors often take longer to resect, which can increase the overall risk. Larger tumors also have greater mass effect and put more nontumor tissue at risk during dissection. In our previous report, we found that when the maximal tumor diameter was greater than 5 $\mathrm{cm}$ on primary resection, the complication rate was $14 \%$ with no morbidity, but we could only achieve a Simpson grade I or II resection in $58 \%$ of cases. ${ }^{21}$ In that series, $47 \%$ of the tumors were located on the skull base. It is not surprising to us that, while trending toward significance, tumor size did not reach statistical significance for complications in our model because reoperation for even small tumors along the skull base can be very challenging; it is the location of the tumor and repeat approach that drives the complications. Thus, fractionated EBRT is the firstline option for recurrent or residual skull base meningiomas to reduce normal tissue toxicity while simultaneously providing good local control. In contrast to radiosurgery, where ablative doses of ionizing radiation are delivered over the course of 1 to 5 days, fractionated EBRT for meningioma involves daily administration of small doses of radiation over the course of 5 to 6 weeks. Multiple singleinstitution retrospective studies have established fractionated radiotherapy as the mainstay of adjuvant treatment for high-grade meningiomas. ${ }^{1,2,5}$ Retrospective data also suggest that low-grade meningiomas that are closely adherent to critical nervous or vascular structures at the skull base can also be effectively treated with EBRT., ${ }^{9,27,32}$ These findings are the subject of multiple ongoing prospective clinical trials, including RTOG 0539, ${ }^{23}$ EORTC $1308,{ }^{12}$ and NRG-BN003 (clinical trial no. NCT03180268; clinicaltrials.gov).

For patients who require reoperation despite having undergone primary resection and adjuvant radiotherapy, it has been argued that prior EBRT impairs wound healing and makes microsurgical dissection much more difficult. 
Indeed, in our experience with reoperations, the scar from prior surgical intervention can create significant arachnoiditis by itself. Adding interval radiation therapy for residual disease makes for the most challenging surgical environment at reoperation. Interestingly, we have noticed that the arachnoiditis is usually less if a patient has been treated with radiosurgery or radiation therapy alone compared with prior resection. In the series presented here, prior radiation therapy of any type trended slightly toward increased complications ( $p=0.20$ ), but the difference was not significant on univariate or multivariate analysis. However, only $24 \%$ of the patients in our series had prior radiation therapy before reoperation, which should not have confounded the results. Thus, while not a significant risk factor for complication, it is our experience that prior radiotherapy often makes for a more challenging reoperation compared with no prior radiotherapy.

Finally, the big question to both patients and neurosurgeons is the decision on when to reoperate for recurrence. As discussed above, the primary first-line treatment for meningioma recurrence is radiation therapy. The patient cohort reported in this series is unique in that many of the patients came to our center after they were lost to followup after treatment at other institutions and had a recurrence that was too large to be treated with radiation therapy, or were patients with tumors that had recurred despite receiving radiation therapy, and thus, required reoperation. However, for the patients monitored closely in our clinic who develop recurrence with documented growth of greater than $2 \mathrm{~mm} /$ year, we will typically treat the tumors with radiation therapy or radiosurgery first while the recurrence is small. If the tumor continues to grow and is refractory to radiation therapy, then we will discuss with the patient when to reoperate. If the patient is symptomatic from the recurrence, then the decision to resect the tumor may be relatively easy. However, when the patient is asymptomatic, the decision is more nuanced and requires an ongoing discussion with the patient about what they would like. We hope that the new data reported here on the high rate of complications with reoperation, combined with good survival outcomes, will help to inform the discussion between neurosurgeons and patients as they walk through the evaluation of risks and benefits for each individual situation. Finally, when reoperating for recurrent tumors, the option of interstitial brachytherapy at the time of surgery should be considered, especially for aggressive tumors that are difficult to control. ${ }^{15}$

\section{Limitations}

As a retrospective study, analysis and interpretation was limited by the quality and availability of information in EMRs. Our medical center is a referral center for the treatment of meningiomas, and many patients who underwent primary resection of skull base meningiomas at outside institutions lacked records of this original surgery. Furthermore, neurological and medical complications were likely to be underreported because they are not typically documented quite as robustly as surgical complications. Nonetheless, our cohort of 78 patients who underwent at least 1 reoperation for skull base meningiomas is among the largest samples in the current literature.

\section{Generalizability}

The results reported here are those obtained by a quaternary neurosurgical center in the hands of an experienced surgeon. They should be generalizable to many other centers with similar expertise, but may not be generalizable to all neurosurgeons and certainly not to those who are not experienced skull base surgeons at a high-volume center.

\section{Conclusions}

Reoperation for recurrent skull base meningiomas can lead to excellent long-term survival, but it is associated with a high complication rate. Tumor location in the posterior fossa is associated with a higher risk of complications.

\section{Acknowledgments}

This work was supported by the Linda Wolfe Meningioma Research Fund and the National Cancer Institute of the National Institutes of Health (grant no. 1F32CA213944-01) to S.T.M.

\section{References}

1. Adeberg S, Hartmann C, Welzel T, Rieken S, Habermehl D, von Deimling A, et al: Long-term outcome after radiotherapy in patients with atypical and malignant meningiomas-clinical results in 85 patients treated in a single institution leading to optimized guidelines for early radiation therapy. Int $\mathbf{J} \mathbf{R a}-$ diat Oncol Biol Phys 83:859-864, 2012

2. Aghi MK, Carter BS, Cosgrove GR, Ojemann RG, AminHanjani S, Martuza RL, et al: Long-term recurrence rates of atypical meningiomas after gross total resection with or without postoperative adjuvant radiation. Neurosurgery 64:56-60, 2009

3. Bambakidis NC, Kakarla UK, Kim LJ, Nakaji P, Porter RW, Daspit CP, et al: Evolution of surgical approaches in the treatment of petroclival meningiomas: a retrospective review. Neurosurgery 62 (6 Suppl 3):1182-1191, 2008

4. Borba LAB, de Oliveira JG, Giudicissi-Filho M, Colli BO: Surgical management of foramen magnum meningiomas. Neurosurg Rev 32:49-60, 2009

5. Boskos C, Feuvret L, Noel G, Habrand JL, Pommier P, Alapetite $\mathrm{C}$, et al: Combined proton and photon conformal radiotherapy for intracranial atypical and malignant meningioma. Int J Radiat Oncol Biol Phys 75:399-406, 2009

6. Chen CM, Huang APH, Kuo LT, Tu YK: Contemporary surgical outcome for skull base meningiomas. Neurosurg Rev 34:281-296, 2011

7. Chicani CF, Miller NR: Visual outcome in surgically treated suprasellar meningiomas. J Neuroophthalmol 23:3-10, 2003

8. Fischer BR, Brokinkel B: Surgical management of skull base meningiomas - an overview, in Monleon D (ed): Meningiomas. Management and Surgery. Rijeka, Croatia: InTech, 2010

9. Goldsmith BJ, Wara WM, Wilson CB, Larson DA: Postoperative irradiation for subtotally resected meningiomas. A retrospective analysis of 140 patients treated from 1967 to 1990. J Neurosurg 80:195-201, 1994

10. Hentschel SJ, DeMonte F: Olfactory groove meningiomas. Neurosurg Focus 14(6):e4, 2003

11. Jääskeläinen J: Seemingly complete removal of histologically benign intracranial meningioma: late recurrence rate and factors predicting recurrence in 657 patients. A multivariate analysis. Surg Neurol 26:461-469, 1986

12. Jenkinson MD, Javadpour M, Haylock BJ, Young B, Gillard $\mathrm{H}$, Vinten J, et al: The ROAM/EORTC-1308 trial: Radiation versus Observation following surgical resection of Atypical 
Meningioma: study protocol for a randomised controlled trial. Trials 16:519, 2015

13. Jung HW, Yoo H, Paek SH, Choi KS: Long-term outcome and growth rate of subtotally resected petroclival meningiomas: experience with 38 cases. Neurosurgery 46:567-575, 2000

14. Klinger DR, Flores BC, Lewis JJ, Hatanpaa K, Choe K, Mickey B, et al: Atypical meningiomas: recurrence, reoperation, and radiotherapy. World Neurosurg 84:839-845, 2015

15. Magill ST, Lau D, Raleigh DR, Sneed PK, Fogh SE, McDermott MW: Surgical resection and interstitial iodine-125 brachytherapy for high-grade meningiomas: a 25 -year series. Neurosurgery 80:409-416, 2017

16. Nakamura M, Roser F, Struck M, Vorkapic P, Samii M: Tuberculum sellae meningiomas: clinical outcome considering different surgical approaches. Neurosurgery 59:1019-1029, 2006

17. Nakamura M, Struck M, Roser F, Vorkapic P, Samii M: Olfactory groove meningiomas: clinical outcome and recurrence rates after tumor removal through the frontolateral and bifrontal approach. Neurosurgery 62 (6 Suppl 3):12241232,2008

18. Nanda A, Vannemreddy P: Recurrence and outcome in skull base meningiomas: do they differ from other intracranial meningiomas? Skull Base 18:243-252, 2008

19. O'Sullivan MG, van Loveren HR, Tew JM: The surgical resectability of meningiomas of the cavernous sinus. Neurosurgery 40:238-247, 1997

20. Ostrom QT, Gittleman H, Fulop J, Liu M, Blanda R, Kromer C, et al: CBTRUS Statistical Report: Primary Brain and Central Nervous System Tumors Diagnosed in the United States in 2008-2012. Neuro Oncol 17 (Suppl 4):iv1-iv62, 2015

21. Quiñones-Hinojosa A, Kaprealian T, Chaichana KL, Sanai N, Parsa AT, Berger MS, et al: Pre-operative factors affecting resectability of giant intracranial meningiomas. Can J Neurol Sci 36:623-630, 2009

22. Roberti F, Sekhar LN, Kalavakonda C, Wright DC: Posterior fossa meningiomas: surgical experience in 161 cases. Surg Neurol 56:8-21, 2001

23. Rogers L, Zhang P, Vogelbaum MA, Perry A, Ashby L, Modi $\mathrm{J}$, et al: RTOG 0539A: Intermediate-risk meningioma: initial outcomes from NRG Oncology/RTOG-0539. Int J Radiat Oncol Biol Phys 93 (3 Suppl):S139-S140, 2015

24. Russell SM, Benjamin V: Medial sphenoid ridge meningiomas: classification, microsurgical anatomy, operative nuances, and long-term surgical outcome in 35 consecutive patients. Neurosurgery 62 (3 Suppl 1):38-50, 2008

25. Seifert V: Clinical management of petroclival meningiomas and the eternal quest for preservation of quality of life: personal experiences over a period of 20 years. Acta Neurochir (Wien) 152:1099-1116, 2010

26. Sughrue ME, Sanai N, Shangari G, Parsa AT, Berger MS, McDermott MW: Outcome and survival following primary and repeat surgery for World Health Organization Grade III meningiomas. J Neurosurg 113:202-209, 2010
27. Taylor BW Jr, Marcus RB Jr, Friedman WA, Ballinger WE Jr, Million RR: The meningioma controversy: postoperative radiation therapy. Int J Radiat Oncol Biol Phys 15:299-304, 1988

28. Topsakal C, Al-Mefty O, Bulsara KR, Williford VS: Intraoperative monitoring of lower cranial nerves in skull base surgery: technical report and review of 123 monitored cases. Neurosurg Rev 31:45-53, 2008

29. Turgut M, Ozcan OE, Benli K, Ozgen T, Gürcay O, Bertan $\mathrm{V}$, et al: Factors affecting morbidity and mortality following surgical intervention in patients with intracranial meningioma. Aust N Z J Surg 66:144-150, 1996

30. Velho V, Agarwal V, Mally R, Palande DA: Posterior fossa meningioma "our experience" in 64 cases. Asian J Neurosurg 7:116-124, 2012

31. von Elm E, Altman DG, Egger M, Pocock SJ, Gøtzsche PC, Vandenbroucke JP: The Strengthening the Reporting of Observational Studies in Epidemiology (STROBE) statement: guidelines for reporting observational studies. PLoS Med 4:e296, 2007

32. Wenkel E, Thornton AF, Finkelstein D, Adams J, Lyons S, De La Monte S, et al: Benign meningioma: partially resected, biopsied, and recurrent intracranial tumors treated with combined proton and photon radiotherapy. Int J Radiat Oncol Biol Phys 48:1363-1370, 2000

33. Wiemels J, Wrensch M, Claus EB: Epidemiology and etiology of meningioma. J Neurooncol 99:307-314, 2010

34. Zeng L, Wang L, Ye F, Chen J, Lei T, Chen J: Clinical characteristics of patients with asymptomatic intracranial meningiomas and results of their surgical management. Neurosurg Rev 38:481-488, 2015

\section{Disclosures}

The authors report no conflict of interest concerning the materials or methods used in this study or the findings specified in this paper.

\section{Author Contributions}

Conception and design: Magill, McDermott. Acquisition of data: Magill, Lee, Yen, Lucas. Analysis and interpretation of data: Magill, Lee, Yen, Raleigh, Theodosopoulos, McDermott. Drafting the article: Magill, Lee, McDermott. Critically revising the article: Magill, Yen, Raleigh, Aghi, Theodosopoulos, McDermott. Reviewed submitted version of manuscript: Magill, Lee, Yen, Raleigh, McDermott. Approved the final version of the manuscript on behalf of all authors: Magill. Statistical analysis: Magill, Yen. Study supervision: Magill, McDermott.

\section{Correspondence}

Stephen T. Magill: University of California, San Francisco, CA. stephen.magill@ucsf.edu. 